\title{
A Practical, Stepwise Approach to Peanut Oral Immunotherapy in Clinical Practice: Benefits and Risks
}

\author{
Aikaterini Anagnostou ${ }^{1,2}$ \\ 'Baylor College of Medicine, Section of \\ Pediatric Immunology, Allergy and \\ Rheumatology, Houston, TX, USA; \\ ${ }^{2}$ Texas Children's Hospital, Department \\ of Pediatrics, Section of Immunology, \\ Allergy and Rheumatology, Houston, \\ TX, USA
}

This article was published in the following Dove Press journal: Journal of Asthma and Allergy

\begin{abstract}
Food allergies are common, affecting 6-8\% of the children in the United States. There is a significant burden on the quality of life of allergic children and their caregivers, due to multiple dietary, social and psychological restrictions. Peanut allergy affects approximately $2-5 \%$ of the school-age children. Despite the recommended dietary avoidance, reactions tend to occur due to unintentional exposures and the fear of accidental ingestions potentially resulting in anaphylaxis and death, which creates a lot of anxiety in peanutallergic individuals. Peanut oral immunotherapy (POIT) has emerged as a form of active treatment and has shown high efficacy in research trials with the majority of participants achieving desensitization and protection from trace exposures. An improved quality of life has also been noted following successful POIT. The risks of POIT should be balanced against the benefits resulting from successful treatment for each individual. Rates of allergic reactions and anaphylaxis are reported to be higher in individuals pursuing therapy, but most subjects will experience mild or moderate reactions during treatment. The landscape of peanut allergy management is changing and the future offers more options for patients than were previously available. Shared decision-making, which is the process of how to choose between different available options, becomes an ongoing discussion between the clinician and the patient, which will ensure achievement of the best possible outcome for the peanut-allergic child. This is a multistep process that evaluates the benefits and risks of therapy or no therapy, as well as patient and family preferences and we review it in detail in this manuscript with the aim to provide clinicians with a practical approach.
\end{abstract}

Keywords: food allergy, anaphylaxis, children, epinephrine, peanut, food challenge, oral immunotherapy, desensitization, sustained unresponsiveness, shared decision-making, decision aids

\section{Introduction}

Food allergies are common, affecting $6-8 \%$ of the children ${ }^{1,2}$ and they have a significant effect on the quality of life of allergic children and their caregivers. ${ }^{3}$ Peanut allergy affects $2-5 \%$ of the US school-age children. ${ }^{4,5}$ Peanut-allergic patients often display significant anxiety, which stems mostly from their fear of accidental ingestion with potentially severe reactions, including anaphylaxis and death. Peanut-allergic children face various dietary, social restrictions and psychological issues at school (such as bullying). ${ }^{6-9}$ Peanut allergy tends to be lifelong and rarely resolves, with only one in five children outgrowing it during childhood. ${ }^{10}$ There is currently no cure and the traditional approach is based on patient
Correspondence: Aikaterini Anagnostou Baylor College of Medicine, Section of Pediatric Immunology, Allergy and

Rheumatology, II 02 Bates Avenue Ste 330, Houston, TX 77030, USA

$\mathrm{Tel}+\mid$ 832-824-1319

Fax +1 832-825- 1260

Email Aikaterini.Anagnostou@bcm.edu
Journal of Asthma and Allergy 2021:14 277-285 
education, strict avoidance and prompt treatment of adverse reactions when they occur. Unfortunately, accidental exposures occur despite avoidance with a recent review reporting an average of $10 \%$ per year for peanut. ${ }^{5}$ Children and families are provided with emergency medication (antihistamines and epinephrine auto-injectors) and a management plan on how to treat allergic reactions. ${ }^{11}$

Over the last decade, peanut oral immunotherapy (POIT) has emerged as a form of active and potentially diseasemodifying treatment for peanut allergy. POIT involves the administration of small, gradually increasing doses of peanut with the aim to enable patients to eat varying amounts without reactions. Most research studies include an initial up-dosing phase (with or without a "rush" escalation), which usually lasts a few weeks or months, and a long-term maintenance phase once the desired maintenance dose is reached. For example, in the PALISADE study, the initial dose escalation day involved administration of five doses of peanut protein every 20-30 minutes: $0.5 \mathrm{mg}, 1 \mathrm{mg}, 1.5 \mathrm{mg}, 3 \mathrm{mg}$ and $6 \mathrm{mg}$. This was followed by the slow escalation phase were doses were increased every 2 weeks at the following levels: $3 \mathrm{mg}$, 6mg, $12 \mathrm{mg}, 20 \mathrm{mg}, 40 \mathrm{mg}$, 80mg, 120mg, $160 \mathrm{mg}, 200 \mathrm{mg}, 240 \mathrm{mg}$ and $300 \mathrm{mg}$, which is the maintenance dosing level. The maintenance phase lasts for years and currently, ongoing regular ingestion is advised as maintenance therapy. "Desensitization" refers to a rise in the allergenic threshold of reactivity and implies regular dose ingestion (usually a daily dose) in order to maintain the desensitized state. 'Sustained unresponsiveness' refers to the ability of subjects who have successfully completed an oral immunotherapy protocol, to discontinue treatment for a few weeks or months and then return to daily allergen consumption at their previous dose, without any allergic reactions. "Long-term tolerance" is defined as the ability to eat the previously allergenic food ad lib at any amount or frequency without any problems or the need for daily dosing. ${ }^{12-14}$ Rates of desensitization vary between published reports (rates: $62 \%-89 \%)^{15-20}$ as do sustained unresponsiveness rates (reported $13-50 \%{ }^{21,22}$ ). It is important to clearly define the above terms and explain their meaning to participating patients and their families.

\section{POIT Evaluation and the Shared Decision-Making Process in the Allergy Clinic}

We describe a case illustration (please note this is not a real case, but a case illustration created specifically to discuss shared decision-making steps) of a peanut-allergic patient presenting in the allergy clinic with her parents who are considering POIT.

Lilly,a 5-year-old girl, diagnosed with peanut allergy following a moderate allergic reaction to peanut butter at the age of 2 years, confirmed with strong positive skin prick testing. She has avoided peanut successfully for the first year after diagnosis, but as she grew older, she has experienced multiple accidental exposures to peanutcontaining products and her parents are frustrated and wish to consider alternative management options. The parents are both scientists and have two children. They have already researched POIT online and in social media. They present in the allergy clinic inquiring about this "new therapy". Their first question is how effective POIT is likely to be for their daughter and what are the limitations of therapy.

Prior to initiating the discussion on the benefits of POIT, the physician reviews the child's medical record and asks about any health problems to ensure there are no contraindications to participation in POIT for instance, uncontrolled asthma (see Table 1 for full list of contraindications to POIT). Parents report that Lilly is in perfect health apart from her peanut allergy. The benefits and

Table I POIT Aims and Contraindications

\begin{tabular}{|l|}
\hline POIT Aims \\
\hline Protection from accidental trace exposures \\
Ability to reintroduce varying amounts* of peanut into the diet \\
Improvement in quality of life \\
\hline POIT contraindications \\
\hline Uncontrolled or severe asthma \\
Active eosinophilic esophagitis \\
Severe gastroesophageal reflux, dysphagia or any chronic undiagnosed \\
GI condition \\
Inability to follow protocols or non-compliance with regular dosing \\
Pregnancy or breast feeding \\
Undergoing build-up for another form of immunotherapy at the same \\
time (ie, allergy shots) \\
History of life-threatening anaphylaxis to peanut requiring ICU \\
admission \\
Any chronic condition that affects safety during POIT or may become \\
exacerbated due to POIT \\
Any concomitant medication that affects response to epinephrine (ie, \\
$\beta$-blockers, angiotensin-converting enzyme inhibitors, angiotensin \\
receptor blockers) \\
History of mast cell disorder \\
History of drug, alcohol or medication abuse
\end{tabular}

Note: *Amount depends on study protocol and maintenance dose. 
limitations of POIT are described to the family and the following data is shared.

POIT efficacy is high with the majority of participants achieving desensitization (the term is also explained to the family). The PALISADE trial, the largest international POIT trial to date, which included a total number of 551 participants (496 were children) has confirmed the high efficacy of OIT; $67.2 \%$ of the active participants compared to only $4 \%$ placebo participants were able to ingest a single $600 \mathrm{mg}$ dose of peanut (cumulative dose more than $1000 \mathrm{mg}$ peanut protein content) at the exit food challenge without dose-limiting symptoms. ${ }^{18}$ In another, smaller US trial investigators have reported that in a randomized controlled study of 28 peanut-allergic participants, $84 \%$ of the active subjects passed a final challenge of 20 peanuts (approximately $5000 \mathrm{mg}$ peanut protein), compared with only 1 peanut (approximately $280 \mathrm{mg}$ peanut protein; peanut content is variable depending on the size of the peanut) tolerated by the placebo subjects in the final challenge, after completing a year of OIT. The study regimen was well tolerated with clinically relevant symptoms seen after only $1.2 \%$ of build-up doses and no peanut OIT subject requiring epinephrine administration. ${ }^{16,23}$ In the private practice setting rates of desensitization have been reported as $79 \%$ in a cohort of 270 patients with peanut allergy, with $23 \%$ of patients requiring epinephrine treatment during escalation. ${ }^{19,24}$ In a different community private practice, $89 \%$ of 783 patients (children and adults) with peanut allergy reached maintenance dose. ${ }^{20}$

Limitations of POIT include lack of sustained unresponsiveness in the majority of patients and life-long therapy for the large majority of patients. On a daily basis, the exercise restriction for 2 hours after dosing, as well as the effect of other co-factors (illness, tiredness, sleep deprivation, NSAIDs, alcohol consumption) are also discussed as limitations of the therapy (Table 2).

At this point, dad reports that he was born and raised in Switzerland and is concerned his European background may affect efficacy of the intervention.

The physician reassures the father that results appear similar in a European population, with a Phase II, randomized-controlled, crossover trial of peanut oral immunotherapy (OIT) originating from the UK successfully achieving desensitization in the majority of 99 children, aged 7-16 years, inclusive of all severities of peanut allergy. Following completion of the intervention, in the active group, $84 \%$ were desensitized to 5 peanuts (approximately $800 \mathrm{mg}$ peanut protein), whereas 62\%
Table 2 Benefits and Risks of POIT

\begin{tabular}{|l|l|}
\hline Benefits & Risks \\
\hline High efficacy & Frequent side effects \\
\hline $\begin{array}{l}\text { Side effects mostly mild or } \\
\text { moderate }\end{array}$ & Anaphylaxis in 10-35\%* \\
\hline $\begin{array}{l}\text { Desensitization occurs } \\
\text { within a few months }\end{array}$ & $\begin{array}{l}\text { Practical limitations and co-factor } \\
\text { effect (exercise, illness, tiredness, } \\
\text { sleep deprivations, NSAIDs) }\end{array}$ \\
\hline $\begin{array}{l}\text { Larger amounts tolerated } \\
\text { over time }\end{array}$ & Taste aversion \\
\hline Less side effects over time & Continued carriage of epinephrine \\
\hline $\begin{array}{l}\text { Protective effect against } \\
\text { accidental trace exposures }\end{array}$ & $\begin{array}{l}\text { Unknown protection against large } \\
\text { accidental exposures, but likely less } \\
\text { severe reactions after desensitization }\end{array}$ \\
\hline Improvement in quality of life & Likely life-long therapy, not a cure \\
\hline
\end{tabular}

Note: *Different rates are reported in different studies.

of OIT participants successfully passed a 10-peanut challenge. $^{25}$ ARTEMIS, a different European-based trial of peanut OIT also supports good efficacy, with $58 \%$ of 132 participants in the peanut OIT group tolerated $1000 \mathrm{mg}$ peanut protein at the exit food challenge versus only $2 \%$ of 43 participants in the placebo group. ${ }^{17}$ The maximum severity of adverse events reported was mild or moderate for most participants who received POIT (mild, 50\% of 132 participants; moderate, $48 \%$; and severe, one $1 \%$ ). ${ }^{17}$ The physician stresses that the above studies provide strong evidence that oral immunotherapy for peanut allergy is a form of active therapy that has high efficacy in different geographical populations of children allergic to peanuts. The time from the beginning of treatment to achieving maintenance is usually between 6 and 12 months and the treatment has high success rates.

The family wants to know what level of protection is achieved after POIT. Can their daughter eat all peanutcontaining products? How will her daily dietary (and other) restrictions change following successful therapy?

Protection from accidental trace exposures is a significant clinical benefit of POIT and this is explained to the family by sharing the following data on threshold changes. A reported rise in threshold from less than $100 \mathrm{mg}$ of peanut protein to $300 \mathrm{mg}$ post-immunotherapy has been shown to reduce the risk of experiencing an allergic reaction by more than $95 \%$ for various food products with potential peanut contamination. ${ }^{26} \mathrm{~A}$ further increase to 
$1000 \mathrm{mg}$ peanut protein has an additional quantitative benefit in risk reduction. ${ }^{26}$ Therefore, patients that are successfully desensitized may relax their restrictions with regards to eating outside the home (for example, restaurants where cross-contact may occur) and eating products with precautionary labeling. The physician informs the parents, however, that reaching a maintenance dose of $300 \mathrm{mg}$ would not allow their daughter to consume peanut ad-lib and avoidance of the allergen is still recommended. It is discussed that different patients and families may opt for different levels of maintenance dosing - $300 \mathrm{mg}$ if the goal is to achieve protection from accidental exposures versus much larger amounts (4-6 $\mathrm{g}$ of peanut protein) if the aim is to consume large amounts of peanut or more concentrated forms such as peanut butter.

The question is now posed to the family as to what their goals of treatment are and what they expect to achieve with POIT. Both parents agree that they wish for their daughter to be protected from unintentional trace exposures and if a larger accidental ingestion occurs, they would hope for a less severe reaction.

Indeed, current research suggests that in case of significant accidental exposures, allergic reactions are likely to be lower in severity following therapy ${ }^{18}$ and this is shared with the family. It is stressed that emergency medication must be carried despite successful desensitization, as this therapy is not curative for peanut allergy and reactions may still occur. The parents agree to that and comment that they always ensure their daughter's emergency medications are available.

The discussion continues with a focus on quality of life changes. Studies have shown that protection from inadvertent exposures driven by increases in the eliciting dose results in improved quality of life (QoL). The STOP II trial from the UK showed significant QoL improvement following successful desensitization. ${ }^{25}$ Blumchen et al also reported significant improvement in QoL in 62 children undergoing low-dose peanut OIT in a multicenter, double-blind, randomized placebocontrolled trial. ${ }^{27}$ Epstein-Rigbi et al showed that the QoL of 191 children with food allergy improved significantly upon reaching OIT maintenance, with additional improvement 6 months later. $^{28}$ The caregivers' QoL also improved in a trial of multi-allergen food immunotherapy. ${ }^{29,30}$ QoL is an important patientreported outcome and OIT appears to have a positive effect on the daily life of sufferers.

\section{The Mother Wants to Know the Risks of POIT for Her Daughter: Is Anaphylaxis Likely to Occur During Therapy?}

The physician replies that the main risk of POIT is indeed allergic reactions to treatment and that generally, rates of adverse reactions and anaphylaxis are reported to be higher in individuals pursuing therapy options. ${ }^{31}$ However, in POIT most subjects will likely experience mild or moderate reactions during treatment (most of these will occur in the up-dosing or early maintenance phases), ${ }^{18}$ with the frequency and number of reactions generally decreasing during the longer-term maintenance phase. It has also been suggested that adverse events are significantly associated with allergic rhinitis and SPT wheal size therefore, it is highly recommended that any co-morbid allergic condition is well controlled before initiating POIT. ${ }^{32}$ The STOP II trial reported mild side effects in the majority of participants, with gastrointestinal symptoms being the most common. Intramuscular epinephrine was required for one participant only $(0.01 \%$ of doses). ${ }^{25}$ No participant required more than one administration of epinephrine and there were no therapy-related hospitalizations. In the PALISADE peanut OIT trial, adverse events occurred in more than $95 \%$ of participants 4-17 years of age, with mild events noted in 34.7\%, moderate in $59.7 \%$ and severe in $4.3 \%{ }^{18}$ Anaphylaxis was reported in $14.2 \%$ of the active participants and in $3.2 \%$ of the placebo participants in the PALISADE trial. Of the reactions requiring epinephrine in the active arm, $92.7 \%$ were treated with one dose, $6.1 \%$ with two doses and $1.2 \%$ with three doses of epinephrine. In the placebo arm, all reactions were successfully treated with a single epinephrine dose. Overall, 43 participants $(11.6 \%)$ in the active group and $3(2.4 \%)$ in the placebo group withdrew from the trial because of adverse events during the intervention period. ${ }^{18}$ Additionally, higher rates of anaphylaxis (over 20\%) have been reported in other studies, with a systematic review noting a $22 \%$ risk of anaphylaxis with oral immunotherapy. ${ }^{31}$ In the private practice setting, rates of $10-23 \%$ have been reported. ${ }^{19,20}$ The physician explains that training in the use of epinephrine autoinjectors will be offered to the parents in every POIT visit.

Another important side effect of treatment is the development of taste aversion to peanut over time for a proportion of desensitized patients. This can vary from mild aversion to taste to severe aversion when therapy is discontinued. A recent report examining long-term follow- 
up of POIT showed that $10 \%$ of the patients discontinued treatment due to taste aversion and concluded that patients who liked or were indifferent to peanuts were more likely to continue treatment, while patients with significant food aversion were more likely to discontinue treatment. ${ }^{33}$

\section{Mom Mentions That She Has Also Heard That POIT is Associated with "Some Sort of Inflammation of the Food Pipe"}

The question regarding esophageal inflammation is addressed. The parents' knowledge appears to be limited in this area, so the physician begins by describing what EoE refers to, before moving on to the OIT-related risk of this condition. A published meta-analysis reports that approximately $3 \%$ of the patients with IgE-mediated food allergies undergoing OIT developing this complication, with EoE often resolving following discontinuation of treatment. ${ }^{34}$ However, individual studies have reported variable rates and the available data are limited. Goldberg et al recently described OIT-induced gastrointestinal symptoms associated with peripheral eosinophilic responses in 65 patients who were receiving OIT for milk, peanut, egg or sesame. ${ }^{35}$ According to their report, these symptoms abated following dosage modifications or temporary discontinuation of treatment, half of the patients were able to achieve full desensitization and more than two-thirds were able to achieve partial desensitization. A starting dose of more than $120 \mathrm{mg}$, a second month dose more than fourfold over the starting dose and baseline absolute eosinophil count of over $600 / \mu \mathrm{L}$ were all identified as risk factors of developing transient gastrointestinal symptoms associated with peripheral eosinophilia. ${ }^{35}$

\section{The Mother Asks What Would Happen if Her Daughter Becomes III During POIT and Cannot Take Her Dose}

This question provides a window of opportunity to discuss the effect of external factors (or co-factors) such as viral illnesses, tiredness and exercise, which have the potential to lower the threshold of reactivity in patients undergoing OIT. $^{36}$ The recently published TRACE study ${ }^{37}$ provided evidence that exercise and sleep deprivation each significantly reduce the threshold of reactivity in patients with peanut allergy, putting them at greater risk of a reaction. ${ }^{37}$ The physician explains that treatment may be required to stop briefly or the dose may need to be reduced during periods of illness. For example, in the case of an acute viral illness, the dose may be decreased by $50 \%$ for the duration of the illness. The same applies to tiredness and sleep deprivation. It is explained to the parents that a written action plan will be provided to them with specific instructions on what to do in these circumstances. Exercise restrictions are also discussed and the physician notes that children need to avoid exercise for 2 hours after dosing. The family is educated on the management of external factors and how this will improve risk management during OIT and ensure better safety while undergoing therapy. It is also explained by the physician that the effect of these cofactors remains during maintenance also, as reactions may still occur during the maintenance phase, albeit less frequently.

\section{The Family Has Also Read on Facebook That POIT is Very Intense and Time-Consuming and They Wish to Understand the Level of Commitment Required}

This is a very important part of the conversation, as OIT is an intervention that requires time, dedication and motivation from both patients and their family. The practical, everyday aspects of POIT may seem daunting for some families or underestimated by others, so the physician should be able to put the process in the right context and timeframe. Most POIT schedules require a 2-3-hour visit every 2 weeks for the first 6 months or so (until the maintenance dose is reached). Therefore, time off work and also off school may be required for children and families and needs to be taken into consideration. Lack of flexibility in scheduling would make this process rather challenging and may be a barrier to participation. The family set-up and dynamics should be examined carefully also. Noncollaborative family interactions or lack of commitment from parents or patients is usually prohibiting. In a two-parent household, both should be onboard for this intervention and consent should be obtained from each parent individually. Patient assent is also encouraged in an age-appropriate manner; children aged 7 years and older may be able to provide this and usually have a reasonable understanding of what the intervention entails. Obtaining a social history is also valuable. The distance of the family's home from the allergy clinic (where appointments will be scheduled) as well as from the nearest ED (in case severe allergic reactions occur), are 
important factors to consider. Any other family members suffering from peanut allergy and living in the same household, must also be taken into account for safety issues.

\section{The Mother is Asking if She Can Give Lilly Probiotics with POIT Because a Friend of Hers Has Told Her That "These Help with Allergic Reactions When the Child is Undertaking POIT"}

Information related to use of probiotics comes from an Australian study and is shared with the parents. In children with peanut allergy, this study evaluated the effects of probiotics as an adjuvant to peanut OIT. The trial enrolled 31 children with confirmed peanut allergy who were allocated to the probiotic and peanut OIT group and received L. rhamnosus along with peanut OIT once daily up to a maintenance dose of $2 \mathrm{~g}$ peanut protein. Additionally, 31 children received both a probiotic placebo and an OIT placebo once daily. The investigators reported that $82.1 \%$ in the probiotic and POIT group achieved sustained unresponsiveness (after 2 or more weeks of therapy discontinuation) compared to only $3.6 \%$ in the placebo group $(\mathrm{P}<0.001) .{ }^{38}$ A follow-up study 4 years after treatment cessation, reported that $58 \%$ of participants from the probiotic and POIT group attained 8-week sustained unresponsiveness, compared with $7 \%$ of participants from the placebo group $(\mathrm{p}=0 \cdot 012) .{ }^{39}$ The physician notes that the above studies comparing peanut OIT and probiotic with placebo OIT and placebo probiotic unfortunately fail to answer the question on whether probiotic use improves the outcome of peanut OIT. A study comparing subjects, all of whom receive peanut OIT and split between receiving probiotic or placebo probiotic would be more appropriate. Therefore, probiotic use is not recommended as an adjuvant to POIT, based on current evidence. On the other hand, probiotics are generally shown to be safe and well tolerated by patients, so if the mother wishes to administer a probiotic this should not be a problem, as long as it is clearly explained that the effect on POIT is currently unknown.

The family asks if their other child, a 5-month-old boy would be eligible for POIT. He has not yet been introduced to peanut, but the parents plan to do early introduction around 6 months and want to know if this therapy would be effective for him if he reacts to peanut.
The following information is shared with the family. POIT appears to be highly efficacious in the preschool age group. A study by Vickery et al showed that $78 \%$ of 40 preschool children achieved sustained unresponsiveness following an average of 29 months of OIT, with $71 \%$ tolerating $3000 \mathrm{mg}$ peanut protein. ${ }^{40}$ Most importantly, longer-term follow-up at 5 years post-treatment showed the majority of these children continuing dietary peanut consumption, with 55\% ingesting more than $1000 \mathrm{mg}$ peanut protein without any allergic reactions. ${ }^{41}$ It has been suggested that early age may provide a window of opportunity for treatment, as young children potentially display clinical and immunological characteristics that are more responsive to treatment interventions. However, the physician encourages the parents to proceed with early introduction (their son has no risk factors based on the national guidelines for early introduction) and re-evaluate at a later time.

Finally, the physician outlines the benefits and risks of "no therapy" to the family, which should also be considered prior to a decision. The family is offered time to think about all the information they have received and a followup consultation is arranged. Written information on POIT is also provided.

\section{In Summary}

The scenario described in this manuscript is becoming more common in the allergy clinic and the question of how to approach the consultation with a patient and family who are considering POIT is an important one. In practical terms, the first step is to confirm the food allergy diagnosis (this may require a food challenge if in doubt), followed by an assessment of the patient's eligibility for this type of therapy. The physician should ensure that there are no comorbidities that may preclude the patient from participating (for example, active EoE or uncontrolled asthma). Next, risks and benefits of the procedure should be clearly outlined and discussed at length with the patient and the family. This will likely be an ongoing discussion and shared decision-making is crucial as shown above. Finally, it is worth considering the family set-up and dynamics; this therapy requires dedication and a motivated individual/family. If there are concerns about treatment compliance, it would be best to defer OIT initiation until these are fully addressed and resolved.

Parents receive a tremendous amount of information nowadays from friends, social media and the internet. 
Often, there is a lot of misinformation that has to be addressed directly in the allergy clinic. Tackling misconceptions can be challenging, especially if the source is considered reliable and trustworthy (such as a close friend or family member). A relationship of trust between the family and the physician is crucial for successful treatment and ongoing compliance.

The landscape of food allergies is changing and in addition to traditional avoidance strategies, new options for active therapy are emerging over time, bringing up the question of appropriate decision-making. In peanut, immunotherapy decisions are unlikely to be straightforward. The patient and family will be faced with a variety of potential management paths, each having trade-offs. ${ }^{42}$ The process of how to choose a particular option becomes a discussion where the clinician and the patient have to jointly review the medical evidence as outlined above, but also the patient's preference for balancing particular attributes of the treatment. ${ }^{42}$ Parents may also engage their children in specific decisions, involve them in the management of their condition and prepare them for the transition to greater independence when they reach adulthood. ${ }^{43}$

Decision support tools, such as decision aids, are starting to emerge for peanut allergy therapy. These may assist patients in understanding and choosing between new treatments and available options and by balancing decisions with personal values. ${ }^{44}$ They also help address caregiver goals, expectations, and psychological barriers as well as identify facilitators for treatment strategies. ${ }^{45,46}$ Additionally, educational tools may be helpful, such as counseling videos and patient checklists; these are being evaluated with the aim to improve parent and patient knowledge of OIT in the outpatient clinic setting. ${ }^{47}$

\section{Conclusions}

There is no doubt that patients with peanut allergy carry a significant daily burden. For a very long time, the only available option for the management of their disease has been avoidance of peanut and treatment of unintentional exposures when these occurred. Recently, the emergence of POIT as an active therapy has changed the traditional approach to peanut allergy management and expanded the offerings for children with peanut allergy. Making the right decision for therapy differs for each patient and their family. Balancing risks and benefits of POIT versus no therapy requires review of the current evidence by both provider and patient, as well as significant personal input on the patient's preferences. It is expected that shared decision- making and use of decision aids will become routine in the allergy clinic over time and will have the potential to assist caregivers and patients in making the decision that best fits their treatment goals and family values.

\section{Abbreviations}

ED, emergency department; EoE, eosinophilic esophagitis; OIT, oral immunotherapy; POIT, peanut oral immunotherapy; SU, sustained unresponsiveness; QoL, quality of life.

\section{Disclosure}

Aikaterini Anagnostou is the Principal Investigator for Aimmune Therapeutics research trials and receives Institutional grant funding. The author reports no other conflicts of interest in this work.

\section{References}

1. Gupta RS, Springston EE, Warrier MR, et al. The prevalence, severity, and distribution of childhood food allergy in the United States. Pediatrics. 2011;128:e9-17. doi:10.1542/peds.2011-0204

2. Jialing J, Warren C, Browning R, et al. R food allergy: epidemiology and racial/ethnic differences. J Food Allergy. 2020;1:11-16.

3. Avery NJ, King RM, Knight S, Hourihane JOB. Assessment of quality of life in children with peanut allergy. Pediatr Allergy Immunol. 2003;14:378-382. doi:10.1034/j.1399-3038.2003.00072.x

4. Bunyavanich S, Rifas-Shiman SL, Platts-Mills TAE, et al. Peanut allergy prevalence among school-age children in a US cohort not selected for any disease. J Allergy Clin Immunol. 2014;134:753-755. doi:10.1016/j.jaci.2014.05.050

5. Capucilli P, Wang KY, Spergel JM. Food reactions during avoidance: focus on peanut. Ann Allergy, Asthma Immunol. 2020;124:459-465. doi:10.1016/j.anai.2020.01.008

6. Stensgaard A, Nielsen D, Munch M, Dunngalvin A. Quality of life in childhood, adolescence and adult food allergy: patient and parent perspectives. Exp Allergy. 2016;530-539. doi:10.1111/cea.12849.

7. Greenhawt M. Food allergy quality of life. Ann Allergy, Asthma Immunol. 2016;113:506-512.

8. Herbert L, Shemesh E, Bender B. Clinical management of psychosocial concerns related to food allergy. J Allergy Clin Immunol Pract. 2016;4:205-213. doi:10.1016/j.jaip.2015.10.016

9. Annunziato RA, Rubes M, Ambrose MA, et al. Longitudinal evaluation of food allergy-related bullying. J Allergy Clin Immunol Pract. 2014;2(5):639-641. doi:10.1016/j.jaip.2014.05.001

10. Burks AW, Tang M, Sicherer S, et al. ICON: food allergy. J Allergy Clin Immunol. 2012;129:906-920. doi:10.1016/j.jaci.2012.02.001

11. Anagnostou K, et al. Active management of food allergy: an emerging concept. Arch Dis Child. 2014:1-5. doi:10.1136/archdischild2014-306278.

12. Anagnostou K, Clark A. What do we mean by oral tolerance? Clin Exp Allergy. 2016;46:782-784. doi:10.1111/cea.12751

13. Anvari S, Anagnostou K. The nuts and bolts of food immunotherapy: the future of food allergy. Child (Basel, Switzerland). 2018;1-9. doi:10.3390/children5040047

14. Ak S, Am S. Food allergy oral immunotherapy. J Food Allergy. 2020;1:75-80.

15. Anagnostou K, Islam S, King Y, et al. Assessing the efficacy of oral immunotherapy for the desensitisation of peanut allergy in children (STOP II): a Phase 2 randomised controlled trial. Lancet. 2014;38 3:1297-1304. 
16. Varshney P, Jones SM, Scurlock AM, et al. A randomized controlled study of peanut oral immunotherapy: clinical desensitization and modulation of the allergic response. J Allergy Clin Immunol. 2011;127:654-660. doi:10.1016/j.jaci.2010.12.1111

17. Hourihane JO, et al. Efficacy and safety of oral immunotherapy with AR101 in European children with a peanut allergy (ARTEMIS): a multicentre, double-blind, randomised, placebo-controlled Phase 3 trial. Lancet Child Adolesc Heal. 2020;4642.

18. Vickery BP, et al. AR101 oral immunotherapy for peanut allergy. N Engl J Med. 2018;379:1991-2001.

19. Wasserman RL, Hague AR, Pence DM, et al. Real-World experience with peanut oral immunotherapy: lessons learned from 270 patients. $J$ Allergy Clin Immunol Pract. 2019;7(418-426.e4):418-426.e4. doi:10.1016/j.jaip.2018.05.023

20. Afinogenova Y, Rubin TN, Patel SD, et al. Community private practice clinical experience with peanut oral immunotherapy. J. Allergy Clin. Immunol. Pract. 2020;8:2727-2735. doi:10.1016/j. jaip.2020.03.016

21. Chinthrajah RS, Purington N, Andorf S, et al. Sustained outcomes in oral immunotherapy for peanut allergy (POISED study): a large, randomised, double-blind, placebo-controlled, phase 2 study. Lancet. 2019;394:1437-1449. doi:10.1016/S0140-6736(19)31793-3

22. Vickery BP, Scurlock AM, Kulis M, et al. Sustained unresponsiveness to peanut in subjects who have completed peanut oral immunotherapy. J. Allergy Clin. Immunol. 2014;133:468-475. doi:10.1016/j.jaci.2013.11.007

23. Varshney P, Jones SM, Pons L, et al. Oral Immunotherapy (OIT) induces clinical tolerance in peanut-allergic children. J. Allergy Clin. Immunol. 2009;123:S174-S174. doi:10.1016/j.jaci.2008.12.656

24. Wasserman RL, Factor JM, Baker JW, et al. Oral immunotherapy for peanut allergy: multipractice experience with epinephrine-treated reactions. J Allergy Clin Immunol Pract. 2014;2:91-96. doi:10.10 16/j.jaip.2013.10.001

25. Anagnostou K, Islam S, King Y, et al. Assessing the efficacy of oral immunotherapy for the desensitisation of peanut allergy in children (STOP II): a phase 2 randomised controlled trial. Lancet. 2014;383 (9925):1297-1304.

26. Baumert JL, Taylor SL, Koppelman SJ. Quantitative assessment of the safety benefits associated with increasing clinical peanut thresholds through immunotherapy. J Allergy Clin Immunol Pract. 2017. doi:10.1016/j.jaip.2017.05.006

27. Blumchen K, Trendelenburg V, Ahrens F, et al. Efficacy, safety, and quality of life in a multicenter, randomized, placebo-controlled trial of low-dose peanut oral immunotherapy in children with peanut allergy. J Allergy Clin Immunol Pract. 2019;7:479-491.e10. doi:10.1016/j.jaip.2018.10.048

28. Epstein-Rigbi N, Goldberg MR, Levy MB, Nachshon L, Elizur A. Quality of Life of food-allergic patients before, during, and after oral immunotherapy. J Allergy Clin Immunol Pract. 2019;7(429-436.e2). doi:10.1016/j.jaip.2018.06.016

29. Arasi S, Otani IM, Klingbeil E, et al. Two year effects of food allergen immunotherapy on quality of life in caregivers of children with food allergies. Allergy Asthma Clin Immunol. 2014;10(57):57. doi:10.1186/1710-1492-10-57

30. Otani I, Bégin P, Kearney C, et al. Multiple-allergen oral immunotherapy improves quality of life in caregivers of food-allergic pediatric subjects. Allergy Asthma Clin Immunol. 2014;10:25. doi:10.1186/1710-1492-10-25

31. Chu DK, Wood RA, French S, et al. Oral immunotherapy for peanut allergy (PACE): a systematic review and meta-analysis of efficacy and safety. Lancet (London, England). 2019;393:2222-2232. doi:10. 1016/S0140-6736(19)30420-9
32. Virkud YV, Burks AW, Steele PH, et al. Novel baseline predictors of adverse events during oral immunotherapy in children with peanut allergy. J. Allergy Clin. Immunol. 2017;139(882-888.e5). doi:10.10 16/j.jaci.2016.07.030.

33. Nachshon L, Goldberg MR, Katz Y, Levy MB, Elizur A. Long-term outcome of peanut oral immunotherapy-Real-life experience. Pediatr Allergy Immunol. 2018;29:519-526. doi:10.1111/pai.12914

34. Lucendo AJ, Arias A, Tenias JM. Relation between eosinophilic esophagitis and oral immunotherapy for food allergy: a systematic review with meta-analysis. Ann Allergy Asthma Immunol. 2014; 113:624-629. doi:10.1016/j.anai.2014.08.004

35. Goldberg MR, Nachshon L, Levy MB, Elizur A, Katz Y. Risk factors and treatment outcomes for Oral Immunotherapy-Induced Gastrointestinal Symptoms and Eosinophilic Responses (OITIGER). J Allergy Clin Immunol Pract. 2019;8:125-131. doi:10.1016/j.jaip. 2019.07.034

36. Anagnostou K, Clark A, King Y, et al. Efficacy and safety of high-dose peanut oral immunotherapy with factors predicting outcome. Clin Exp Allergy. 2011;41:1273-1281. doi:10.1111/j.13652222.2011.03699.x

37. Dua S, Ruiz-Garcia M, Bond S, et al. Effect of sleep deprivation and exercise on reaction threshold in adults with peanut allergy: a randomized controlled study. J. Allergy Clin. Immunol. 2019; (6):1584-1594.e2. doi:10.1016/j.jaci.2019.06.038

38. Tang M, Ponsonby A, Orsini F. Administration of a probiotic with peanut oral immunotherapy: a randomized trial. J Allergy. 2015.

39. Mimi P, et al. Long-term clinical and immunological effects of probiotic and peanut oral immunotherapy after treatment cessation: 4-year follow-up of a randomised, double-blind, placebo-controlled trial. Lancet Child Adolesc Heal. 2017. doi:10.1016/S2352-4642(17) 30041-X

40. Vickery BP, Berglund JP, Burk CM, et al. Early oral immunotherapy in peanut-allergic preschool children is safe and highly effective. $J$ Allergy Clin Immunol. 2017;139(173-181.e8). doi:10.1016/j. jaci.2016.05.027.

41. Herlihy L, et al. Five-year follow-up of early intervention peanut oral immunotherapy. J Allergy Clin Immunol Pract. 2020. doi:10.1016/j. jaip.2020.07.009

42. Anagnostou A, Hourihane JOB, Greenhawt M. The Role of shared decision making in pediatric food allergy management. J Allergy Clin Immunol Pract. 2020;8:46-51. doi:10.1016/j.jaip.2019.09.004

43. Miller VA. Involving youth with a chronic illness in decision-making: highlighting the role of providers. Pediatrics. 2018;142:S142-S148. doi:10.1542/peds.2018-0516D

44. Greenhawt M. Shared decision-making in the care of a patient with food allergy. Ann Allergy, Asthma Immunol. 2020;125:262-267. doi:10.1016/j.anai.2020.05.031

45. Chan ES, Dinakar C, Gonzales-Reyes E, et al. Unmet needs of children with peanut allergy: aligning the risks and the evidence. Ann Allergy Asthma Immunol Off Publ Am Coll Allergy Asthma Immunol. 2020;124:479-486. doi:10.1016/j.anai.2020.01.016

46. Greenhawt M, Shaker M, Winders T, et al. Development and acceptability of a shared decision-making tool for commercial peanut allergy therapies. Ann Allergy Asthma Immunol Off Publ Am. Coll Allergy Asthma Immunol. 2020;125(1):90-96. doi:10.1016/j.anai.20 20.01.030

47. Mack DP, Foster GA, Bouwers LM, Hanna MA. A counseling video with pre- and posttesting and checklist for oral immunotherapy consent improves participant knowledge. Ann Allergy, Asthma Immunol. 2020;125(468-474.e4). doi:10.1016/j.anai.2020.06.044 


\section{Publish your work in this journal}

The Journal of Asthma and Allergy is an international, peer-reviewed open-access journal publishing original research, reports, editorials and commentaries on the following topics: Asthma; Pulmonary physiology; Asthma related clinical health; Clinical immunology and the immunological basis of disease; Pharmacological interventions and new therapies. The manuscript management system is completely online and includes a very quick and fair peer-review system, which is all easy to use. Visit http://www.dovepress.com/testimonials.php to read real quotes from published authors.

Submit your manuscript here: https://www.dovepress.com/journal-of-asthma-and-allergy-journal 